\title{
Study on the Development Path of Intermediary Based on the Consumers' Shopping Channel Selection
}

\author{
Qingguo Wang * \\ School of Management \\ Wuhan University of Technology, WUT \\ Wuhan, China \\ wqg1997@163.com \\ *Corresponding author
}

\author{
Shaowei Xia \\ School of Management \\ Wuhan University of Technology, WUT \\ Wuhan, China \\ ludasw@126.com
}

\author{
Haile Hui \\ School of Management \\ Wuhan University of Technology, WUT \\ Wuhan, China \\ 454570898@qq.com
}

\begin{abstract}
The development of intermediary on one hand depends on the external environment changes, on the other hand depends on the transaction patterns between buyers and sellers. On the basis of rational agent assumption and from the perspective of what shopping channel the consumer select when they buy different type of goods, this paper intends to obtain the consumer's shopping channel selection tendency model when they buy different type of goods through simulation analysis with the Netlog software, so as to provide development strategies for the intermediary.
\end{abstract}

Keywords-intermediary; shoppingchannel; development path; simulation analysis; netlog

\section{INTRODUCTION}

As the core of market players, consumer's shopping channel selection will directly affect the development of the intermediary. In order to get better development, the intermediary need to analyze consumer's shopping behavior and study their shopping channel selection tendency, so as to find the right development path. The main factors that affect consumer's shopping behavior, especially their shopping channel selection which directly affect whether the intermediary can exist or not in the market, is product category. Based on this study, referencing the statistic shown in TABLE I which is descripted in Marketing Management by Philip Kotler, we divide the product into three following categories:
TABLE I. PURCHASE RATE STATISTICS ABOUT SHOPPING ONLINE

\begin{tabular}{|l|l|c|c|c|c|}
\hline Category & $\begin{array}{c}\text { Purchase } \\
\text { rate }\end{array}$ & Category & $\begin{array}{c}\text { Purchase } \\
\text { rate }\end{array}$ & Category & $\begin{array}{c}\text { Purchase } \\
\text { rate }\end{array}$ \\
\hline Books & $58 \%$ & Music & $50 \%$ & Software & $44 \%$ \\
\hline Tichets & $29 \%$ & $\begin{array}{c}\text { PC } \\
\text { Peripherals }\end{array}$ & $28 \%$ & Clothes & $26 \%$ \\
\hline CD & $24 \%$ & $\begin{array}{c}\text { Hotel } \\
\text { Reservations }\end{array}$ & $20 \%$ & Toy & $20 \%$ \\
\hline Flowers & $17 \%$ & Electronic & $12 \%$ & & \\
\hline \multicolumn{7}{|r}{}
\end{tabular}

digital products: Digital products mainly refer to information, computer software, audio entertainment, which can be transmitted by means of computer network . Such products can be transmitted from one computer network directly to another, such as computer software, music and so on.

non-digital standardized products: The quality, performance, functionality of this kind of products can be intuitive felled, such as computers etc.

non-digital personalized products: This kind of products mainly refers to the non-digital and personalized factors relative products. Consumers need to communicate with merchants face to face to get their personalized information, such as size, style, performance and other features.

Consumer's shopping channel can be summed up in two categories: shopping online (including direct from the manufacture online and from cybermediary) and shopping offline (including direct from the manufacture offline and from middleman offline). Thus, in the model simulation process, simulations were carried out for each of consumer's shopping channels, in order to get consumer's 
shopping channel selection tendency for different type of products.

Referring the Cooperation Model in Netlog Model Libraries, different simulation was carried out for different product type to simulate consumer' shopping channel selection in this paper in order to obtain consumer's shopping channel selection tendency and provide development strategies for intermediaries.

\section{VARIABLES IN SIMULATION MODEL OF CONSUMER SHOPPING CHANNEL SELECTION}

\section{A. Variables in simulation model of online channel and} entity store channel

This model set the variables of simulation model as following on basis of the affecting factors of consumer online shopping channels and traditional entity store shopping channels choice.

1) Dependent variable

The number of shopping by network channels (W-P) and the number of shopping by entity store channels $(\mathrm{C}-\mathrm{P})$ : the initial value is 20 .

2) Independent variable

Delivery-Satisfaction: values range from 0 to 1 , the initial value is 0.32 .

Product-Message-Quality: values range from 0 to 1 , the initial value is 0.31 .

Purchase-Safety: the range is $[0,1]$, initial value 0.14 .

Stride-Length: the range is $[0,0.3]$, set initial value 0.08 .

Purchase-Ability: the range is $[0,99]$, set initial value 5 .

Resource-Competence: the range is [0,200], set initial value is 51 .

3) Control variables

Promotion-Threshold: the value range is $[0,200]$, the initial value is 102 .

Max-Resource-Height: the initial value is 10 .

Select-Probability: the value range is $[0,0.10]$, the initial value is 0.5 .

High-Low-Threshold: the value range is $[0,99]$, the initial value is 5 .

B. Variables in simulation model of channels of direct sale online and cybermediary

1) Dependent variable

Consumer number of channel of direct sale online (WP1) and consumer number of channel of cybermediary (WP2), their initial value are 20 .

2) Independent variable

Product-Abundant; Quality; Cost; Service-Quality; Stride-Length; Purchase-Ability; Resource-Competence.

Analysis and its impact value of each variable is similar to the foregoing interpretation, we make the collection of independent variables as $\mathrm{X}$, then the initial value of the collection is $(0.33,0.22,0.13,0.20,0.08,5$, 51). Among them, the value range of independent var1 to var5 is $[0,1]$, the value range of independent variable 6 (Purchase-Ability) is from $[0,99]$, the value range of independent variable 7(Resource-Competence) is [0,200].
C. Variables in simulation model of channels of direct sale and middleman offline

\section{1) Dependent variable}

Number of consumers who select direct sale offline (C$\mathrm{P} 1)$ and number of consumers who select middleman offline (C-P2), the initial value is 20 .

\section{2) Independent variable}

Price, Convenience, Personal-Demand, Stride-Length, Purchase-Ability, Resource-Competence.

The initial value of the collection $\mathrm{X}$ formed by above independent variables is set as following $(0.27,0.50,0.256$, $0.08,51)$. Among them, the value range of var1 to var4 is $[0,1]$; the value range of var5 and var6 are the same as the former, they are made as system independent variable.

\section{SimULATION ANALYSIS}

\section{A. Simulation Analysis about Shopping Channel Selection of Digital Product}

1) Simulation for channel of direct sale online and channel of cybermediary

Simulation result shown in Fig 1:

From the simulation result shown in Fig 1 we can see that the number of selection of channel of cybermediary (W-P1) did not change significantly, while the number of selection of channel of direct sale online (W-P2) increased more obvious. This shows that under the network environment, consumers prefer to follow the manufacturer's website to place an order for the digital product, and this trend is more and more obvious with the passage of time. Therefore, in the channels of online, the development of cybermediary would be squeezed.

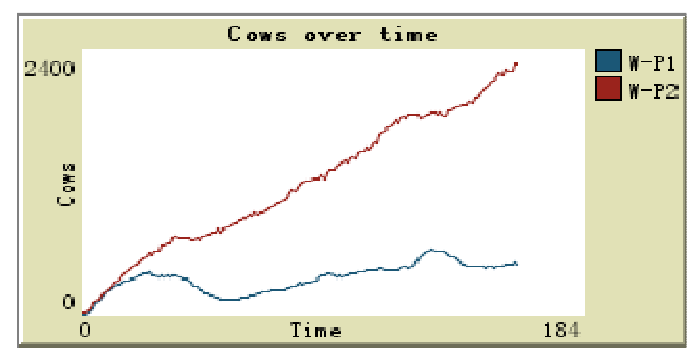

Figure 1. Simulation for direct sale online and cybermediary

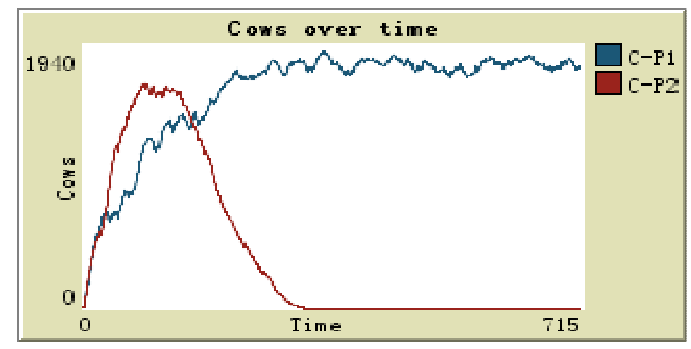

Figure 2. Simulation for direct sale offline and middleman offline 
2) Simulation for channel of direct sale offline and channel of middleman offline

Simulation result shown in Fig 2:

From the simulation result shown in Fig. 2 we can see that, in the channels of offline, consumer mainly tend to buy digital products from middleman (C-P1) in the early, while as consumers shopping experience and their requirements of customization to improve in the process of purchasing digital products, consumers are increasingly inclined to buy directly from manufacture (C-P2). Therefore, for the offline middleman that sell digital products, its development suffer threaten from channels of sales online and direct sales offline. So the offline middleman should change its operation mode from offline to online to get better development.

\section{B. Simulation Analysis about Shopping Channel Selection of Non-Digital Standardized Product}

\section{1) Simulation for channel of online and of offline}

Simulation result shown in Fig 3:

From the simulation result shown in Fig. 3 we can see that with the improvement of consumers online shopping capabilities, the number of consumers who buy non-digital standardized products offline (C-P) gradually reduce, while for the online shopping (W-P) is still on the rise and, with the passage of time, W-P is more consumers than the number of C-P, becoming the main channel for consumers to buy non-digital standardized products.

2) Simulation for channel of direct sale online and channel of cybermediary

Simulation result shown in Fig 4:

From the simulation result shown in Fig 4 we can see that, for the non-digital standardized products, the change trend of channel of direct sale online (W-P1) is similar with that of cybermediary (W-P2), while W-P1 is more consumer than the number of W-P2 most of time. Therefore, for the cybermediary, in order to attract more consumers to obtain greater benefits, they need to take innovation to find better development path.

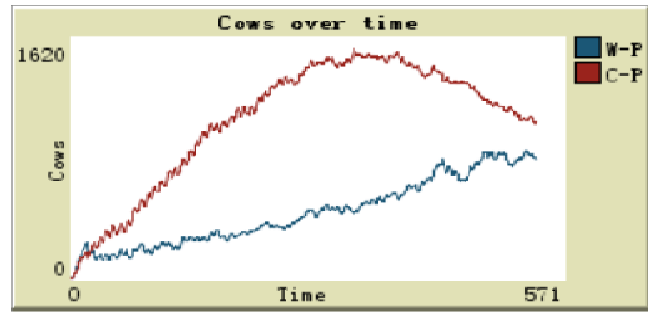

Figure 3. Simulation for channel of online and offline

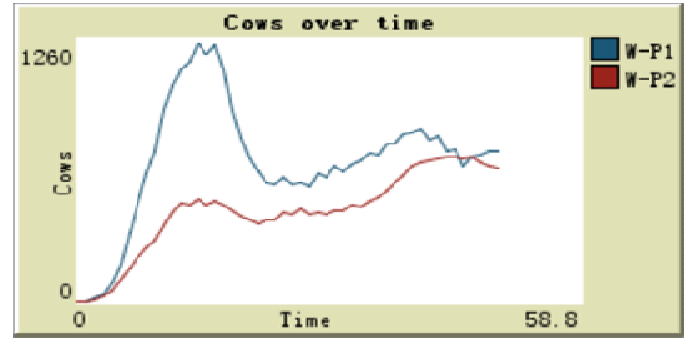

Figure 4. Simulation for channel of direct sale online and cybermediary

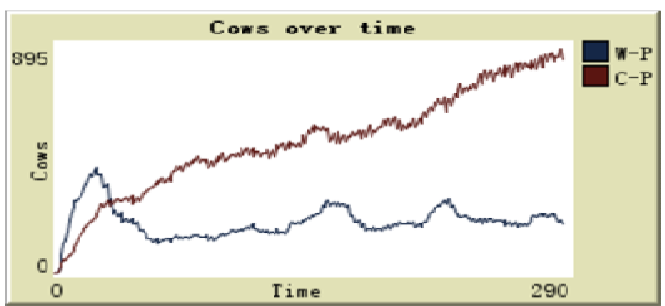

Figure 5. Simulation for channel of online and offline

\section{Simulation Analysis about Shopping Channel} Selection of Non-Digital Personalized Product

1) Simulation for channel of online and channel of offline

Simulation result shown in Fig 5:

From the simulation result shown in Fig 5 we can see that, in the early, the number of consumers who purchase online (W-P) was a little more than that for offline (C-P), while, with the passage of time, more and more consumers tend to purchase personalized products offline. That is because consumers may perceive the convenience of online shopping in the early, thus trying to customize personalized products online, but consumer's demands for personalized products vary from person to person and communication online cannot meet consumer's demand for customizing personalized products, and therefor channel of offline which can allow consumers to communicate with merchants face to face is favored by consumers gradually. For the middlemen who sell personalized products, it is better to select sales offline and make strategies facing to consumer service.

2) Simulation for channel of direct sale offline and channel of middleman offline

Simulation result shown in Fig 6:

From the simulation result shown in Fig 6, we can see that, for the non-digital personalized product, consumers tend to go to direct sale store (C-P1) rather than the distribution store to buy what they need. Consumers pay more attention to the quality of information about the products when they purchase non-digital personalized products, and thus they are inclined to communicate with manufacture directly about the product to obtain their personalized information. Therefore, the middleman 
should improve the level of service to attract more consumers and improve their loyalty.

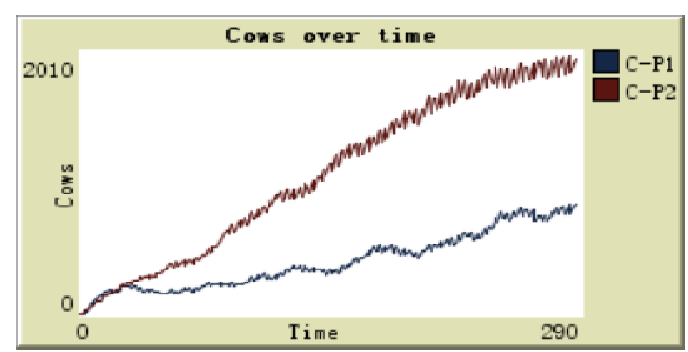

Figure 6. Simulation for channel of direct sale offline and middleman

\section{CONCLUSION}

The simulation results shown above imply that selection of consumer shopping channel vary from different categories of products. And $\mathrm{We}$ can get the following three conclusions from the simulation results:

1) For digital products, direct sale online is preferable;

2) For non-digital standardized products, channel of sale online should be developed rapidly and reduce the sale offline .

3) For non-digital personalized products, channel of direct sale offline should be developed and improve its service level.

\section{ACKNOWLEDGMENT}

This research is financially supported by the Fundamental Research Funds for the Central Universities (Grant No. 2012-IB-003).

\section{REFERENCES}

[1] Philip Kotler. Marketing Management[M]. Shanghai: Shanghai People's Publishing House, 2010.

[2] Guo Yu. Study on Influencing Factors on Online Shoppin [D]. Shanghai Jiaotong University,2012.

[3] JOURNAL OF NANTONG INSTITUTE OF TECHNOLOGY(SOCIAL SCIENCE), 2004, 40(4):22-26.

[4] Geng Liuna, Liyan. Research on Cooperative Behavior of the NetLogo Computer Simulation[J]. MODERN DISTANCE EDUCATION,2011,1(133):66-69.

[5] Liang Xiangyi.Research on Investment Strategy Simulation of Stock Index Futures Market Based on Netlogo[D].Tianjin University,2010.

[6] Pan Yi, Zhang Xing, Gao Li. Research on the Determinants of Purchasing Intention in Online Shopping-From the Perspective of Trust and Perceived Risk [J]. China Industrial Economics, 2010,7:115-120.

[7] Xiao Cuijin. RESEARCH ON FACTORS AND THEIR EFFECT ON YONGSTER BEHAVIOR INTENTION ON ONLINE SHOPPING [D]. Shanghai Jiaotong University,2007. 